\title{
ANALISIS KEMAMPUAN BERPIKIR KRITIS MATEMATIS MELALUI MODEL LEARNING CYCLE 7E DI SEKOLAH MENENGAH
}

\author{
Sri Agustini Dalimunthe ${ }^{1}$, Darta $^{2}$, Thesa Kandaga ${ }^{3}$, Vevi Hermawan ${ }^{4}$ \\ Universitas Pasundan \\ 3thesakandaga@unpas.ac.id
}

\begin{abstract}
ABSTRAK
Penelitian ini merupakan penelitian studi literatur yang memberikan informasi tentang pembelajaran matematika pada sekolah menengah pertama dan sekolah menengah atas dengan model pembelajaran learning cycle $7 e$ terhadap kemampuan berpikir kritis. Tujuan penelitian ini adalah mendeskripsikan kemampuan berpikir kritis melalui model learning cycle 7e. Teknik analisis data menggunakan teknik deduktif, teknik induktif, dan teknik interpretasi. Hasil penelitian menunjukkan bahwa model pembelajaran Learning Cycle $7 E$ pada tingkat sekolah menengah pertama, indikator menentukan tindakan merupakan indikator yang terbesar sedangkan indikator yang paling rendah terdapat pada indikator memfokuskan pertanyaan. Pada tingkat sekolah menengah atas, indikator interpretasi merupakan indikator yang terbesar sedangkan yang paling rendah terdapat pada indikator analisis.
\end{abstract}

Kata kunci: learning cycle 7e, berpikir kritis, studi literatur.

\begin{abstract}
This research is a literature study that provides information about mathematics learning in junior and senior high schools with the 7e learning cycle learning model for critical thinking skills. The purpose of this research is to describe critical thinking skills through the 7e learning cycle model. Data analysis techniques use deductive techniques, inductive techniques, and interpretation techniques. The results showed that Learning Cycle 7E learning model at the junior high school level, the indicator determining action was the largest and the lowest indicator was focusing on questions. In the high school level the interpretation indicator was the largest while the lowest was analysis indicators.
\end{abstract}

Keywords: learning cycle 7e, critical thinking, study literature.

\section{PENDAHULUAN}

Berpikir kritis merupakan bagian dari keterampilan atau kemampuan berpikir tingkat tinggi Alvino 1990 (dalam Agusman 2016, hlm.111-121), karena meliputi proses analisis, sintesis dan evaluasi. Keterampilan berpikir merupakan proses mental yang secara alamiah ketika berpikir. Dengan adanya keharusan dan pembiasaan berpikir kritis dalam pembelajaran diharapkan siswa akan dapat menjadi individu yang kritis. Berdasarkan penjelasan tersebut, kemampuan berpikir kritis matematis sangatlah penting. Namun, pada 
kenyataanya yang sering terjadi di lapangan bahwa kemampuan berpikir kritis matematis siswa masih rendah.

Hasil survey TIMSS ini tidak jauh berbeda dengan hasil survey dari PISA (Coughlan, 2015) pada tahun 2015 Indonesia menduduki rangking 69 dari 76 negara. Mendukung hasil penelitian TIMSS dan PISA sebuah penelitian Lasmanawati (Salamor, 2013, hlm.5) di sebuah SMP Sungailiat, mengungkapkan rata-rata skor postes matematika pada siswa kelas kontrol adalah 9,29 dengan skor ideal 24. Sejalan dengan itu menununjukkan kemampuan berpikir kritis siswa pada salah satu SMP di Sungailiat tergolong rendah. Selain itu berdasarkan hasil penelitian (Syahbana, 2011) rata-rata perolehan siswa ditinjau dari kemampuan berpikir kritis masih tergolong rendah yaitu 1,02.

Banyak faktor yang bisa menyebabkan rendahnya kemampuan berpikir kritis dan tingginya tingkat kecemasan siswa dalam proses pembelajaran. Salah satunya adalah pembelajaran yang berpusat pada guru, seperti yang sering digunakan di sekolah-sekolah selama ini, dimana guru lebih aktif dalam proses belajar sehinga siswa cenderung pasif.

Salah satu pendekatan pembelajaran yang membantu siswa untuk mengembangkan kemampuan berpikir kritis yaitu pendekatan kontruktivisme. Salah satu model yang menggunakan pendekatan kontruktivisme dan dapat memunculkan serta meningkatkan kemampuan berpikir kritis matematis siswa adalah model Learning Cycle 7E.

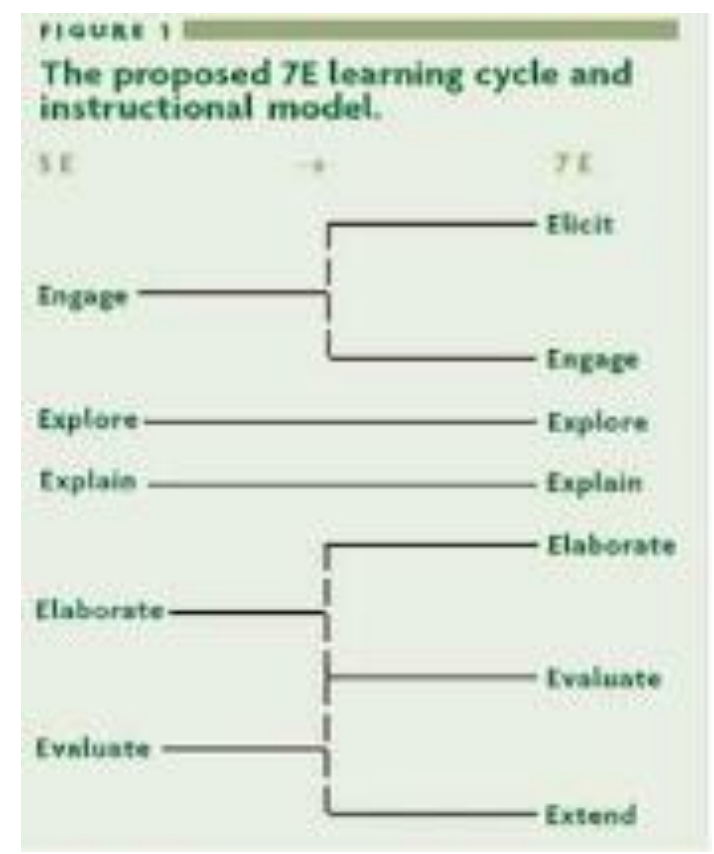

Gambar 1 Peruahan Tahapan Learning Cycle 5E Menjadi 7E (Sumber: Eisenkraft, 2003) 
Model Learning Cycle 7E adalah model yang melalui serangkaian tahapan-tahapan kegiatan yang disusun sedemikian rupa agar siswa dapat menguasai kompetensi yang perlu dicapai sekaligus dapat berperan aktif dalam pembelajaran. Model pembelajaran Learning Cycle terus mengalami perkembangan yang semula dari tiga tahapan kemudian lima tahapan dan sekarang menjadi tujuh tahapan. Perubahan tahapan learning cycle dari $5 E$ menjadi $7 E$ ditunjukkan pada Gambar 1 diatas.

Menurut Eisenkraft (dalam Winidiarti, 2014, hlm.21) tahapan-tahapan model pembelajaran Learning Cycle $7 E$ dapat dijelaskan sebagai berikut: Elicit (mendatangkan pengetahuan awal siswa); Engage (ide, rencana pembelajaran dan pengalaman); Explore (menyelidiki); Explain (menjelaskan); Elaborate (menerapkan); Evaluate (menilai); Extend (memperluas).

Pada artikel ini menjabarkan analisis kemampuan berpikir kritis matematis melalui model learning cycle 7e pada siswa sekolah menengah berdasarkan metode studi literatur.

\section{METODE PENELITIAN}

Teknik Pengumpulan data melalui tahap yang pertama yaitu 1) Editing; 2) Organizing; 3) Finding. Adapun Analisis data penelitian ini menggunakan: 1) Teknik Deduktif; 2) Teknik Induktif; 3) Teknik Interpretasi. Adapun sumber data dalam penelitian ini sumber data dibagi menjadi sumber data primer dan sumber data sekunder. Sumber data primer adalah artikel-artikel nasional maupun internasional yang menjadi pokok bahasan utama dalam penelitian ini. Sedangkan sumber data sekunder merupakan artikel-artikel penunjang dari berbagai jurnal baik jurnal nasional maupun jurnal internasional.

\section{HASIL PENELITIAN}

\section{Kemampuan Berpikir Kritis pada level Sekolah Menengah Pertama}

Hasil penelitian Nuryanti, Zubaidah dan Diantoro (2018) yang menunjukkan siswa mempunyai kategori yang cukup bervariasi. Hasil analisis jawaban siswa dapat dilihat pada Tabel 1 berikut. 
Tabel 1 Hasil Analisis Jawaban Siswa

\begin{tabular}{|c|c|c|c|c|c|}
\hline \multirow[b]{2}{*}{ No. } & \multirow[b]{2}{*}{ Aspek } & \multicolumn{4}{|c|}{ Kategori } \\
\hline & & Benar (\%) & Cukup (\%) & $\begin{array}{c}\text { Kurang } \\
\text { benar }(\%)\end{array}$ & Salah (\%) \\
\hline 1 & $\begin{array}{l}\text { Mengidentifikasi atau menyusun } \\
\text { pertanyaan }\end{array}$ & 89,6 & 10,3 & & \\
\hline 2 & Menganalisis kesimpulan & 27,6 & 41,4 & 27,6 & \\
\hline 3 & $\begin{array}{l}\text { Mengidentifikasi dan mengatasi } \\
\text { ketidakrelevan }\end{array}$ & 27,6 & 51,7 & 17,2 & 0,3 \\
\hline 4 & Mengapa & 62,1 & 20,7 & 17,2 & \\
\hline 5 & Mengapa & 75,8 & 10,3 & 13,8 & \\
\hline 6 & Reputasi & 0,3 & 17,2 & 58,6 & 17,2 \\
\hline 7 & $\begin{array}{l}\text { Interval yang pendek antara observasi } \\
\text { dan laporan }\end{array}$ & 10,3 & 6,8 & 34,5 & 48,3 \\
\hline 8 & Kelas logika & 6,8 & 79,3 & 13,8 & \\
\hline 9 & Menggeneralisasikan & & 37,8 & 48,3 & 13,8 \\
\hline 10 & $\begin{array}{l}\text { Konsekuensi menerima atau menolak } \\
\text { keputusan }\end{array}$ & 68,9 & 31,0 & & \\
\hline 11 & Definisi & 24,1 & 65,5 & 10,3 & \\
\hline 12 & Menilai kebenaran asumsi & & & 93,1 & 6,8 \\
\hline 13 & $\begin{array}{l}\text { Membuat dan mempertimbangkan } \\
\text { keputusan }\end{array}$ & 27,6 & 31,0 & 34,5 & 6,8 \\
\hline 14 & $\begin{array}{l}\text { Mengikuti langkah-langkah } \\
\text { penyelesaian masalah }\end{array}$ & 93,1 & 6,8 & & \\
\hline 15 & $\begin{array}{l}\text { Mengikuti langkah-langkah } \\
\text { penyelesaian masalah }\end{array}$ & 93,1 & 6,8 & & \\
\hline
\end{tabular}

Dari tabel tersebut menjelaskan bahwa kemampuan berpikir kritis siswa SMP disalah satu Kabupaten Klaten tergolong rendah. Hal tersebut dapat diatasi dengan menggunakan model lerning cycle tipe $7 E$ dimana dapat dilihat dari data diagram berikut.

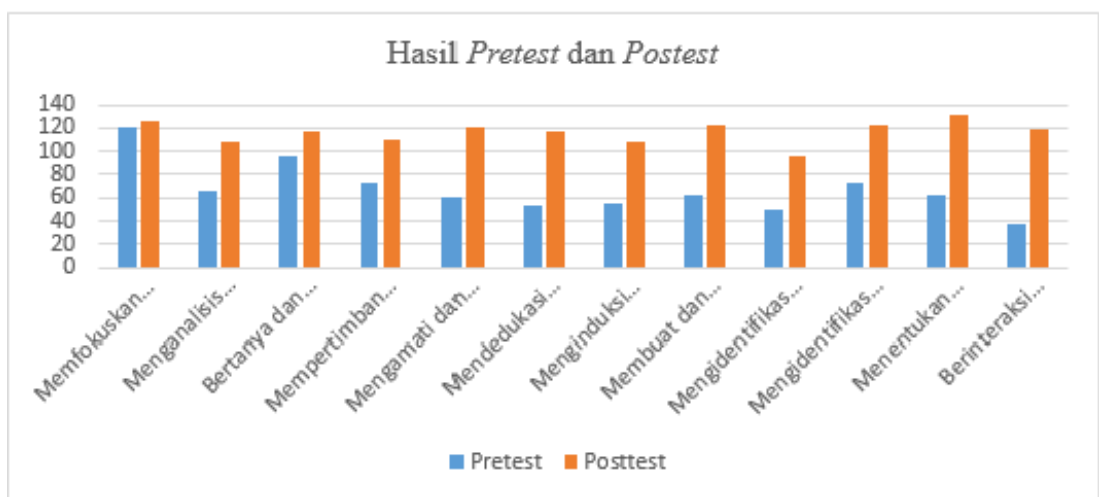

Gambar 2 Hasil Pretest dan postest

Adapun hasil uji $N$ - Gain dapat dilihat pada Gambar 3 berikut ini. 


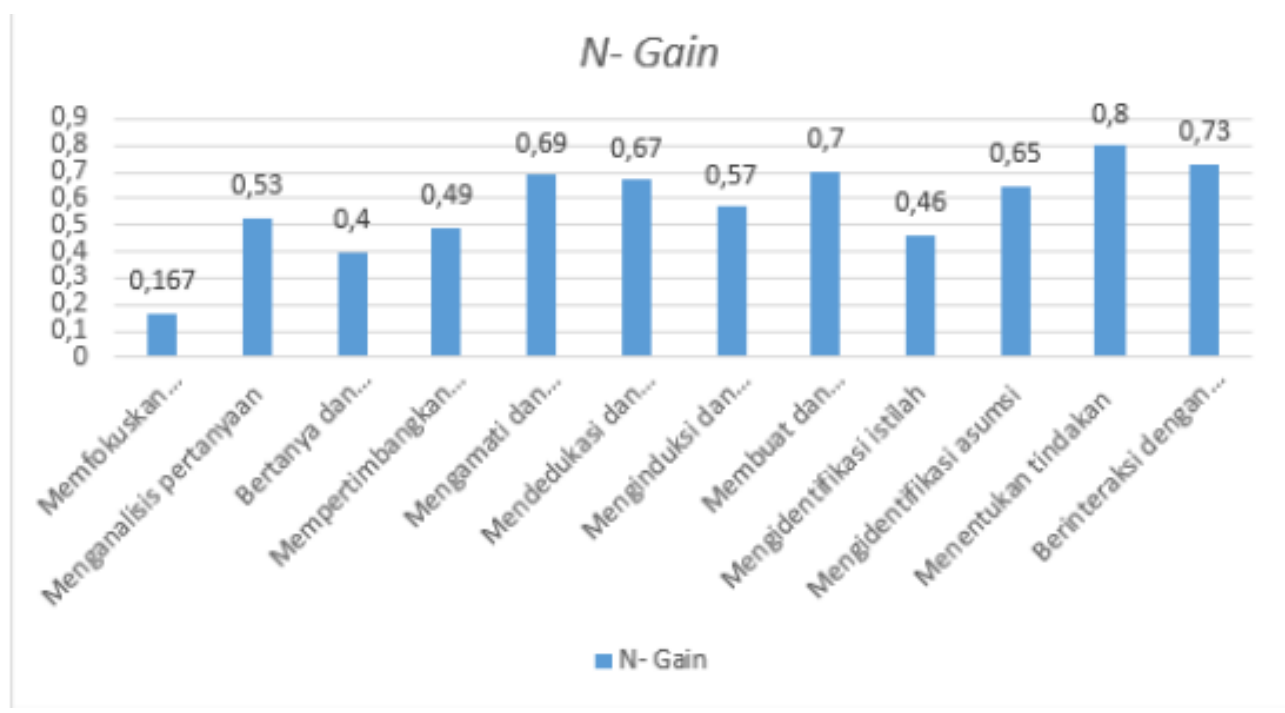

Gambar 3 N-Gain Kemampuan Berpikir Kritis pada level Sekolah Menengah Pertama

Hasil pada gambar 2.2 menunjukkan bahwa siswa menyelesaikan dengan baik soal kriteria "menentukan tindakan".

Kemampuan Berpikir Kritis pada level Sekolah Menengah Atas

Data hasil penelitian Rahyu, dkk (2018) 4 indikator yang digunakan sebagi tolak ukur kemampuan siswa pada penetian ini, yaitu interpretasi, analisis, evaluasi, dan inferensi sebagai berikut:

Tabel 2 Tingkat Kemampuan Berpikir Kritis Siswa per Indikator

\begin{tabular}{lrrrr}
\hline \multirow{2}{*}{ Kategori } & \multicolumn{4}{c}{ Persentase (\%) } \\
\cline { 2 - 5 } & Interpretasi & Analisis & Evaluasi & Inferensi \\
\hline & & & & \\
Sangat tinggi & 26.47 & 14.71 & 27.45 & 18.63 \\
Tinggi & 60.78 & 25.49 & 52.94 & 33.33 \\
Sedang & 9.80 & 37.25 & 15.69 & 31.37 \\
Rendah & 2.94 & 13.73 & 2.94 & 7.84 \\
Sangat rendah & 0.00 & 8.82 & 0.98 & 8.82 \\
\hline
\end{tabular}

Selanjutnya, tingkat kemampuan berpikir kritis siswa secara keseluruhan dapat dilihat pada Tabel 3.

Tabel 3 Tingkat Kemampuan Berpikir Kritis Siswa Soal Keseluruhan

\begin{tabular}{lcc}
\hline \multicolumn{1}{c}{ Kategori } & Jumlah Siswa & Persentase \\
\hline Sangat tinggi & 19 & 18.63 \\
Tinggi & 43 & 42.16 \\
Sedang & 30 & 29.41 \\
Rendah & 10 & 9.80 \\
Sangat rendah & 0 & 0.00 \\
\hline
\end{tabular}


Dari tabel di atas diketahui bahwa tidak ada siswa yang berada pada kategori sangat rendah, dapat disimpulkan bahwa tingkat kemampuan berpikir kritis siswa didominasi kategori tinggi, yaitu 42,16\%.

Hasil penelitian Adnyani, dkk (2018) bahwa terdapat perbedaan

keterampilan berpikir kritis siswa antara siswa yang belajar dengan model learning cycle $7 e$ dan siswa yang belajar dengan model pembelajaran direct instruction:

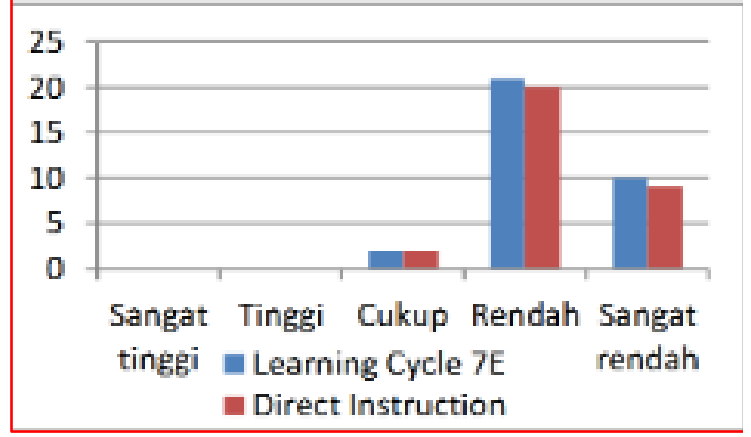

Gambar 4 Grafik Batang Distribusi Frekuensi Skor Pretest

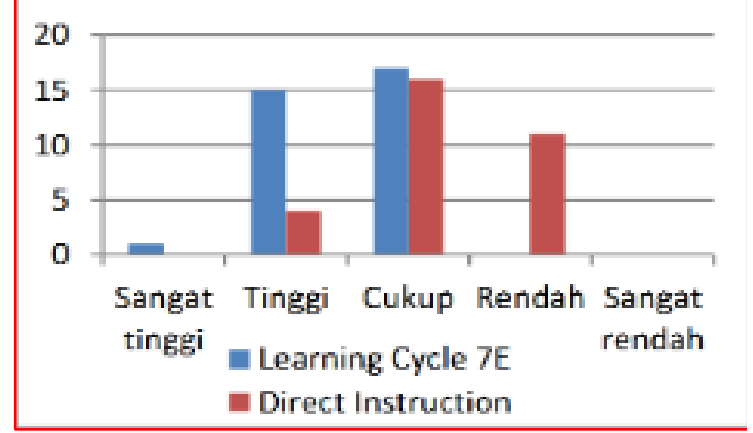

Gambar 5 Grafik Batang Distribusi Frekuensi Skor Postest

Namun terdapat perbedaan peningkatan pada setiap dimensi keterampilan berpikir kritis siswa untuk setiap model serta pada kelompok direct instruction yang ditunjukkan pada tabel di bawah ini:

Tabel 4 Profil Ketercapaian Dimensi Keterampilan Berpikir Kritis

\begin{tabular}{llcc}
\hline No & $\begin{array}{c}\text { Dimensi Keterampilan } \\
\text { Berpikir Kritis }\end{array}$ & $\begin{array}{c}\text { Learning } \\
\text { cycle } 7 \boldsymbol{e}\end{array}$ & $\begin{array}{c}\text { Direct } \\
\text { Instruction }\end{array}$ \\
\hline 1 & Merumuskan masalah & 0.66 & 0.22 \\
2 & Memberikan argumen & 0.52 & -0.50 \\
3 & Melakukan induksi & 0.52 & 0.60 \\
4 & Melakukan deduksi & 0.48 & 0.59 \\
5 & Melakukan evaluasi & 0.65 & 0.29 \\
6 & Memutuskan dan & 1.00 & 0.55 \\
\hline
\end{tabular}

Tabel 4 menunjukkan bahwa siswa yang belajar dengan model learning cycle $7 e$ dan model pembelajaran direct instruction dilihat dari hasil pretest dan hasil posttest sebagian besar mengalami peningkatan pada setiap dimensi keterampilan berpikir kritis, kecuali pada indikator memberikan argumen.

\section{Pengaruh Model Learning Cycle 7e Ditinjau dari Pretest dan Postest}

Penulis mendapatkan data hasil pretest dan postes setelah diberi perlakuan dengan menggunakan model learning cycle 7e: 
Tabel 5 Kumpulan Data Pretest dan Postes Siswa

\begin{tabular}{crrrrrr}
\hline \multirow{2}{*}{ Kode Artikel } & \multicolumn{2}{c}{ Pretest } & \multirow{2}{*}{ Rata-rata } & \multicolumn{2}{c}{ Postest } & \multirow{2}{*}{ Rata-rata } \\
\cline { 2 - 3 } & \multicolumn{1}{c}{ Min } & Max & & \multicolumn{1}{c}{ Min } & \multicolumn{1}{c}{ Max } & \\
\hline Artikel 3 & 12 & 48 & 26,55 & 27 & 94 & 54,73 \\
Artikel 4 & 22,22 & 61,11 & 37,69 & 33,33 & 88,88 & 64,41 \\
Artikel 5 & 45 & 95 & 69 & 60 & 80 & 69,447 \\
\hline
\end{tabular}

Berdasarkan data di atas, dapat dilihat bahwa learning cycle $7 e$ berpengaruh positif terhadap hasil belajar siswa. Walaupun demikian peningkatan terjadi pada setiap nilai minimum pretest dan postest lalu rata-rata yang mengalami peningkatakn sebesar 0,447. Penurunan pada nilai maksimum pretest dan postest disebabkan perlakuan dengan model pembelajaran Learning Cycle hanya menggunakan treatment satu kali.

\section{Peningkatan berpikir kritis dari N-gain}

Berdasarkan hasil penelitian pada artikel yang sudah penulis kumpulkan, dirangkum hasil N-gain dalam bentuk tabel dibawah ini:

Tabel 6 Kumpulan Data N-Gain

\begin{tabular}{cc}
\hline Kode Artikel & N-Gain \\
\hline Artikel 1 & 0,49 \\
Artikel 2 & 0,67 \\
Artikel 6 & 0,56 \\
Artikel 7 & 0,60 \\
Artikel 8 & 0,66 \\
Artikel 9 & 0,810 \\
Artikel 10 & 0,69 \\
\hline
\end{tabular}

Dari tabel diatas, menunjukkan bahwa kualitas berpikir kritis siwa dengan menggunakan model learning cycle $7 E$ berada pada rentang $0,30<\mathrm{g} \leq 0,70$ yang termasuk dalam kategori sedang.

\section{Besar Pengaruh (Koefisien Determinasi)}

Selanjutkan akan dicari seberapa besar nilai pengaruh variabel bebas (model learning cycle $7 e$ ) terhadap variabel terikat (berpikir kritis). Berikut data yang didapatkan penulis:

Tabel 7 Data Kumpulan Koefisien Determinasi

\begin{tabular}{cc}
\hline Kode Artikel & $\begin{array}{c}\text { Koefisien } \\
\text { Determinasi }\end{array}$ \\
\hline Artikel 1 & $36,00 \%$ \\
Artikel 5 & $86,36 \%$ \\
\hline
\end{tabular}

Pada artikel 1, pengaruh model learning cycle $7 e$ terhadap hasil belajar sebesar 36,00\% sedangkan sisanya 64\% dipengaruhi oleh faktor lain. Pada artikel 5 bahwa pengaruh model pembelajaran Learning Cycle $7 e$ adalah sebesar $86,36 \%$ sedangkan sisanya $13,64 \%$ dipengaruhi oleh faktor lain. 


\section{KESIMPULAN}

Berdasarkan hasil analisis dalam penelitian ini, pada tingkat sekolah menengah pertama indikator menentukan tindakan adalah yang terbesar dan indikator yang paling rendah adalah indikator memfokuskan pertanyaan. Untuk tingkat sekolah menengah atas indikator interpretasi adalah yang terbesar sedangkan yang paling rendah adalah indikator analisis. Jika dilihat dari hasil pretest dan postes, terjadi peningkatan setiap nilai minimum dan maksimum pada pretest ataupun nilai minimum dan maksimum pada postest yang dimana rata-rata pada nilai pretest dan postest mengalami peningkatan. Dari data hasil uji N-Gain menunjukkan bahwa rata-rata klasifikasi peningkatan kemampuan berpikir kritis termasuk dalam kategori sedang. Berdasarkan data koefisien determinasi. Pengaruh model pembelajaran Learning Cycle $7 e$ terhadap berpikir kritis sebesar 86,36\% sedangkan sisanya $13,64 \%$ dipengaruhi oleh faktor lain. Sedangkan pengaruh model learning cycle $7 e$ terhadap hasil belajar siswa sebesar $36,00 \%$ sedangkan sisanya $64 \%$ dipengaruhi oleh faktor lain.

\section{REFERENSI}

Adyani, W., Pujani, N, M., dan Juniartina, P, P. (2018). Pengaruh Model Learning Ccyle 7E Terhadap Keterampilan Berpikir Kritis Siswa. 1(2): 57-66.

Agusman. (2016). Desain Model Pembelajaran Matematika yang Mengembangkan Kemampuan Berpikir Kritis: Jurnal Pendidikan Matematika. 2(2): 111-121.

Coughlan S. (2015). Asia Peringkat Tertinggi Sekolah Global Indonesia Nomor 69. Koresponden Pendidikan BBC. Diakses dari www.bbc.com/indonesia/majalah/ 2015/05/150513_majalah_asia_sekolah_terbaik pada tanggal tanggal 20 Februari 2020

Chukwuyenum, A.N. (2013). Impact of Critical thinking on Performance in Mathematics among Senior Secondary School Students in Lagos State.IOSR Journal of Research \& Method in Education. 3(5): 19.

Eisenkraft, Arthur, 2003 "Expanding The 5E Models: A Purposed 7E Models Emphasizes 'Transfer Learning' and The Importance of Eliciting Prior Understanding". The Science Teacher. 70(6): 57.

Ennis, R.H. (1996). A Critical Thinking. New York: Freeman.

Fajaroh, F. Dasna, I, W. (2007). Pembelajaran dengan Model Siklus Belajar (Learning Cycle). Diakses dari http://lubisgrafura.wordpress.com/2007/09/20/ pembelajaran-dengan-model-siklus-belajar-learning-cycle/ pada tanggal 19 Februari 2020.

Lorsbach. 2008. The Learning Cycle as a Tool for Planning Science Intruction. Diakses dari http://www.coe.ilstu.edu/ pada tanggal 19 Februari 2020.

Meltzer, D.E. (2002). The Relationship between Mathematics Preparation and Conceptual Learning Grains in Physics: A Possible "Hidden Variable" in Diagnostice Pretest Scores. American Journal Physics. 70(12): 27. 
Mufidah, N, D. dan Effendi, N. (2018). Penerapan Model Pembelajaran Learning Cycle 7E Untuk Meningkatkan Kemampuan Berpikir Kritis Siswa. 2(2): 109-120.

Muijs, Daniel dan David, R. (2008). Effective Teaching. Yogyakarta: Pustaka Belaja.

Nisak Siti Khoirun, Hadi Syaiful. (2015). Analisis Proses Berpikir Kritis Siswa Dalam Menyelesaikan Soal Peluang. Prosiding Seminar Nasional Pendidikan Matematika. Tulungagung. Januari 2015

Rahayu, D, N, G., Harijanto, A., Lesmona, A, D. (2018). Tingkat Kemampuan Berpikir Kritis Siswa Pada Materi Fluida Dinamis 7(2): 162-167.

Raudlatuzahra, P., Putra, Y. G (12 Agustus 2017). Pengaruh Penerapan Model Pembelajaran Learning Cycle 7E Terhadap Kemampuan Koneksi dan Kecemasan Matematis Siswa SMA. Seminar Nasional Matematika Dan Pendidikan Matematika, Semarang.

Sholihah, I.S. (2012). Pengaruh Model Pembelajaran Learning Cycle 7e terhadap Kemampuan Koneksi Matematis Siswa SMP. Skripsi Pada FKIP UNPAS Bandung: Tidak Diterbitkan.

Susanto, H. P. (2016). Analisis Hubungan Kecemasan, Aktivitas, dan Motivasi Berprestasi dengan Hasil Belajar Matematika Siswa. Jurnal Tadris Matematika. 9(2): 134-147.

Syahbana, Ali. 2012. Peningkatan Kemampuan Berpikir Kritis Matematis Siswa SMP melalui Pendekatan Contextual Teaching and Learning, Jurnal Edumatica. 2(1): 45-57.

Windiarti, Z. (2014). Perbedaan Kemampuan Penalaran Adaptif Siswa yang Diajar Menggunakan Model Pembelajaran Learning Cycle 7e dengan Model Pembelajaran Konvensional pada Materi Luas Permukaan Balok Kelas VIII SMP Negeri 17 Surabaya. Diakses pada tanggal 19 Februari 2020 dari: http://digilib.uinsby.ac.id/850/2/Bab\%201.pdf 